\title{
Parametric Sensitivity Analysis of Factors Affecting Sound Transmission Loss of Multi-Layered Building Elements Using Taguchi Method
}

\author{
Naveen $\operatorname{GARG}^{(1),(2)}$, Anil KUMAR ${ }^{(1)}$, Sagar MAJI ${ }^{(2)}$ \\ (1) Apex Level Standards and Industrial Metrology Division \\ CSIR - National Physical Laboratory \\ New Delhi-110 012, India; e-mail: ngarg@mail.nplindia.ernet.in \\ (2) Department of Mechanical and Production Engineering, Delhi Technological University \\ Delhi-110 042, India
}

(received December 27, 2012; accepted September 23, 2013)

\begin{abstract}
The paper presents application of Taguchi method in optimizing the sound transmission loss through sandwich gypsum constructions and those comprising of masonry concrete blocks and gypsum boards in order to investigate the relative influence of the various parameters affecting the sound transmission loss. The application of Taguchi method for optimizing sound transmission loss has been rarely reported. The present work uses the results analytically predicted on "Insul" software for various sandwich material configurations as desired by each experimental run in an $L_{8}$ orthogonal array. The relative importance of the parameters on single-number rating, $R_{w}\left(C, C_{t r}\right)$ is evaluated in terms of percentage contribution using Analysis of Variance (ANOVA). The ANOVA method reveals that type of studs, steel stud frame and number of gypsum layers attached are the key factors controlling the sound transmission loss characteristics of sandwich multi-layered constructions.
\end{abstract}

Keywords: Spectrum adaptation terms $\left(C, C_{t r}\right)$, Weighted sound reduction index $\left(R_{w}\right), L_{8}$ Orthogonal array $(O A)$, Analysis of Variance (ANOVA), mass-air-mass resonance (m.a.m).

\section{Introduction}

The sound transmission through masonry constructions has always been a grey area of research for its applications in facades and walls in dwellings for outside noise abatement. However, there are not many studies reported so far except those reported by National Research Council, Canada that focus on the enhancement of sound transmission loss through masonry walls in conjunction with the dry wall technology. WARNOCK (1990) reports in this regard provides a large data bank on sound transmission through concrete blocks attached with gypsum boards. The recent studies conducted by Rasmussen (2010), Rasmussen, Rindel (2010) and Scholl et al. (2011) pertaining to the sound regulation criteria in terms of Weighted Standardized Field Level Difference $D_{n T, w}$ and recommendation of fulfilling the criteria $D_{n T, w}+C_{50-3150} \geq$ $55 \mathrm{~dB}$ thus essentially implicates the need of experimental investigations for measuring the sound transmission loss of masonry structures in conjunction with dry wall technology. These investigations are essentially required to ascertain their suitability of meeting the acoustic comfort criteria with an objective of strengthening the building facades. The importance of strengthening the facades is evident from Norwegian study (AMUNDSEN et al., 2011) wherein for noise reduction of $7 \mathrm{~dB}$ inside the dwelling, the percentage highly annoyed respondents dropped from 42 to 16 percent. The experimental investigations on massive concrete and plastered brick structures are practically cumbersome, expensive and time consuming. Thus, the theoretical validated prediction models can be utilized to fill this gap and investigate the pivotal factors affecting the sound transmission loss in terms of single number rating. The method of attachment of gypsum boards via steel studs (staggered, with resilient channels or via double studs), stud spacing, thickness and density of absorptive material used etc are the pivotal factors to be investigated for ascertaining their significance in controlling the sound insulation. 


\section{Cavity depth}

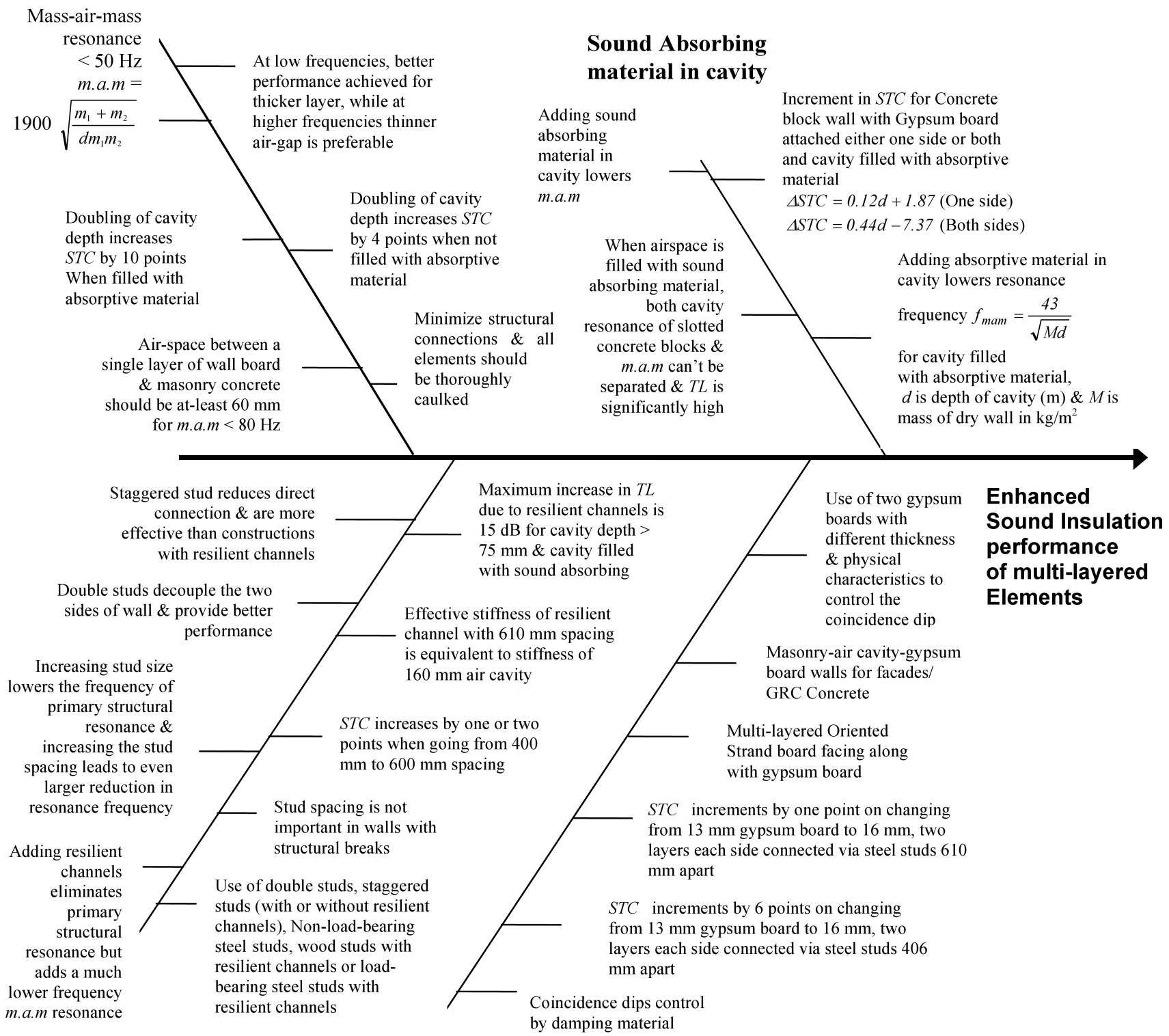

\section{Stud Design Gypsum Board Layers}

Fig. 1. Cause-and-Effect analysis for enhancing sound transmission loss of multi-layered building elements.

All these factors influencing the sound insulation characteristics of multi-layered building elements especially as reported in terms of widely used Sound transmission Class $(S T C)$ rating have been shown in a cause-and-effect analysis diagram based on exhaustive literature survey (BRADLEY, BIRTA, 2000; 2001a; 2001b; HALLIWEll et al., 1998; QUIRT, 1985; WARNOCK, 1985; 1993; WARNOCK, QUIRT, 1997; 1998). Influence of air-cavity on sound reduction has been found to be dependent on frequency. At low frequencies, a better performance is achieved for thicker layers; while at higher frequencies a thinner air-layer is preferable (ANTÓNIO et al., 2003). Attachment via resilient channels and steel studs is instrumental in increasing sound transmission loss. Non-load-bearing steel studs are usually resilient enough to provide adequate mechanical decoupling between layers of gypsum board, while for load bearing steel studs; good results are obtained by use of resilient channels (QUIRT, 1985). Addition of absorptive material in cavity is beneficial only if structural connections between the surfaces don't transmit much vibrational energy. The stud spacing has been investigated to modify the low frequency resonance dips. Structural breaks are achieved by adding gypsum boards using resilient channels or staggered stud constructions. The addition of resilient channels although eliminates the primary structural resonance at $125 \mathrm{~Hz}$, but also introduces a modified 
mass-air-mass resonance (BRADley, BiRTA, 2001a; 2001b). Stud spacing is however not so important in walls where there is a structural break. Increasing the number of gypsum board layers significantly improves the sound transmission loss characteristics due to increased mass resulting in increment of weighted sound reduction index, $R_{w}$ value by $8-9 \mathrm{~dB}$ as observed experimentally in case of changing from one layer to two layers each side attached via steel studs $610 \mathrm{~mm}$ apart.

Although the sound transmission loss in entire frequency range from $50 \mathrm{~Hz}$ to $5 \mathrm{kHz}$ is important, yet dependence upon the single-number ratings has been a contemporary approach followed by manufacturers, engineers and even the acousticians too. The choice of appropriate single number rating is however very important (GARG et al., 2013). The recent investigations pertaining to consideration of single number rating for building elements confirm the suitability of ISO 7171 spectrum adaptation terms in sound regulation requirements for building elements. However, there is no threshold value prescribed for acoustic comfort criteria in dwellings. Recent studies recommend the use of Weighted Standardized Field Level Difference, $D_{n T, w}$ in sound regulation requirements in dwellings (SCHOLL et al., 2011; RASMUSSEN, 2010; RASMUSSEN, RindeL, 2010). $R_{w}+C_{t r}$ is a single-number rating suitable for building facades for evaluating their sound insulation towards traffic noise. The prescriptive approach for walls between dwellings specified for deemed-tosatisfy provisions in Building Codes of Australia has been fixed to $R_{w}+C_{t r}$ not less than 50 when tested in laboratory and $D_{n T, w}+C_{t r}$ not less than 45 when tested on-site (PATterson, 2004). Masonry constructions have been shown to have good low frequency sound insulation characteristics and an $R_{w}+C_{t r}$ value of $69(S T C=79)$ has been experimentally tested for two-leaf concrete block walls (WARNOCK, IR-586). The drywall technology alone suffers from poor low frequency sound insulation characteristics. Even addition of two layers of Oriented stranded boards with two gypsum board layers attached via $140 \mathrm{~mm}$ staggered wood studs and $65 \mathrm{~mm}$ glass fiber batt included in cavity shows an $R_{w}+C_{t r, 50-5 \mathrm{kHz}}$ value of $35 \mathrm{~dB}$ (BRAdley, BirTA, IR-818). Thus, a sandwich multilayered massive construction with drywall attached is a good substitute although practically cumbersome and expensive. GuilLen et al. (2008) observations in this context have revealed that masonry-air cavity-gypsum walls have higher sound reduction index than masonryair cavity-brick ones.

The present study focuses on evaluating the parametric sensitivity of all the factors affecting the sound insulation characteristics of multi-layered building elements consisting of concrete wall constructions attached with gypsum boards. The relative importance of all these parameters on single-number rating $R_{w}(C$,
$\left.C_{t r}\right)$ in frequency range $100 \mathrm{~Hz}$ to $3150 \mathrm{~Hz}$ is evaluated in terms of percentage contribution using Analysis of variance $(A N O V A)$. As the experimental results are practically cumbersome and expensive to perform, so validated software 'Insul $S W$ ' version 7.0.4 was used to analytically predict the sound transmission and single number rating associated with various configurations. Insul is software programme for prediction of sound insulation performance of walls, floors, ceilings and windows. It models material using mass law and coincidence frequency approach and models complex partitions using empirical models of Sharp, Cremer and others. The transmission loss of double panels system is divided into four different frequency regions whereby the effect of shear waves at high frequency is accounted for masonry constructions (Insul Co.). The size of the sample is taken as $2.7 \times 4.0 \mathrm{~m}$. The recent investigations by KURRA (2012) on the development of a prediction model for multilayered building elements confirms the compatibility of Insul model with experimental data. The standard deviation of difference of measured and Insul predicted data is observed to be $4.5 \mathrm{~dB}$ and the correlation coefficient between the calculated and measured laboratory data is high. BALLAGH (2004) investigations evidently reveals a mean difference in $S T C / R_{w}$ between measurement and theory less than $0.5 \mathrm{~dB}$ and $90 \%$ of results were found to lie within $\pm 2.5 \mathrm{~dB}$. Thus, the focus of the present work is to utilize the numerical results predicted from the Insul software in conjunction with application of well known technique of industrial engineering i.e. taguchi method for optimization of sound transmission loss of multi-layered constructions.

\section{Taguchi method}

The Taguchi method developed by Genuchi Taguchi is a statistical method used to improve the product quality and is commonly used in improving industrial product quality (Taguchi techniques for quality engineering, 1995). Taguchi method designs experiments using specially constructed tables known as "orthogonal array" $(O A)$. The use of these tables makes the design of experiments very easy and consistent (Design and analysis of experiments, 1997) and it requires relatively lesser number of experimental trials to study the entire parameter space. The novelty of this approach lies in achieving considerable savings in time, cost, and labour savings. This methodology recommends the use of the signal-to-noise $(S / N)$ ratio to measure the quality characteristics deviating from the desired values. Usually, there are three categories of quality characteristic in the analysis of the $S / N$ ratio, i.e. the-lower-the-better, the-higher-the-better, and the nominal-the-better. A statistical analysis of variance (ANOVA) is performed to examine which process parameters are statistically significant. Thus, the 
optimal combination of the process parameters can be predicted from main effects plot in conjunction with ANOVA analysis.

The selection of an appropriate orthogonal array $(O A)$ requires prior estimation of degrees of freedom. The analysis of variance $(A N O V A)$ is used to investigate the significance of design parameters significantly affecting the quality characteristic, which is accomplished by separating the total variability of the $S / N$ ratios, measured by the sum of the squared deviations from the total mean $S / N$ ratio, into contributions by each of the design parameters and the error. The total sum of squared deviations from means $\left(S S_{T}\right)$ can be calculated as (NALBANT et al., 2007):

$$
S S_{T}=\sum_{i=1}^{n} y_{i}^{2}-\frac{1}{n}\left[\sum_{i=1}^{n} y_{i}\right]^{2},
$$

where $n$ is number of experiments in the orthogonal array (e.g. 8 in $L_{8} O A$ ) and $y_{i}$ is resultant output $\left(R_{w}+C_{t r}\right.$ and $\left.R_{w}+C\right)$ for $i$-th experiment. The total sum of squared deviations is decomposed into two sources: the sum of squared deviations due to each design parameter and the sum of squared error. The sum of squared deviations due to each process parameter $\left(S S_{p}\right)$ is calculated as (NALBANT et al., 2007):

$$
S S_{p}=\sum_{j=1}^{t} \frac{(\bar{y})^{2}}{t}-\frac{1}{n}\left[\sum_{i=1}^{n} y_{i}^{2}\right]^{2}
$$

where $p$ represents one of the experimental parameters, $j$ is the level number of this parameter $p, t$ is the repetition of each level of parameter, $\overline{y_{i}}$ is sum of output involving this parameter $p$ and level $j$.

The sum of squares for each error parameter $\left(S S_{e}\right)$ is in $L_{8} O A$ considering seven parameters at two levels is then calculated as:

$$
S S_{e}=S S_{T}-\sum_{i=1}^{7} S S_{i},
$$

where $S S_{i}$ is sum of squared deviations due to each of the seven design parameters calculated using Eq. (2). The percentage contribution by each of the design parameters is a ratio of the sum of squared deviations due to each design parameter to the total sum of squared deviations (YANG et al., 1998; NALBANT et al., 2007). The mean of squares deviation is calculated as ratio of sum of squared deviations due to each parameter to degree of freedom, wherein degree of freedom of each parameter is $(t-1)$. Thus, the $F$-ratio for each design parameter is calculated as the ratio of the mean of squared deviation to the mean of squared error and is used to statistically ascertain the significance of design variable. The methodology adopted for parametric sensitivity analysis using Taguchi method is shown in Fig. 2. The parametric sensitivity analysis is conducted using design of experiments based ANOVA approach, wherein the significant parameters are analyzed in terms of main effects plot and relative im-

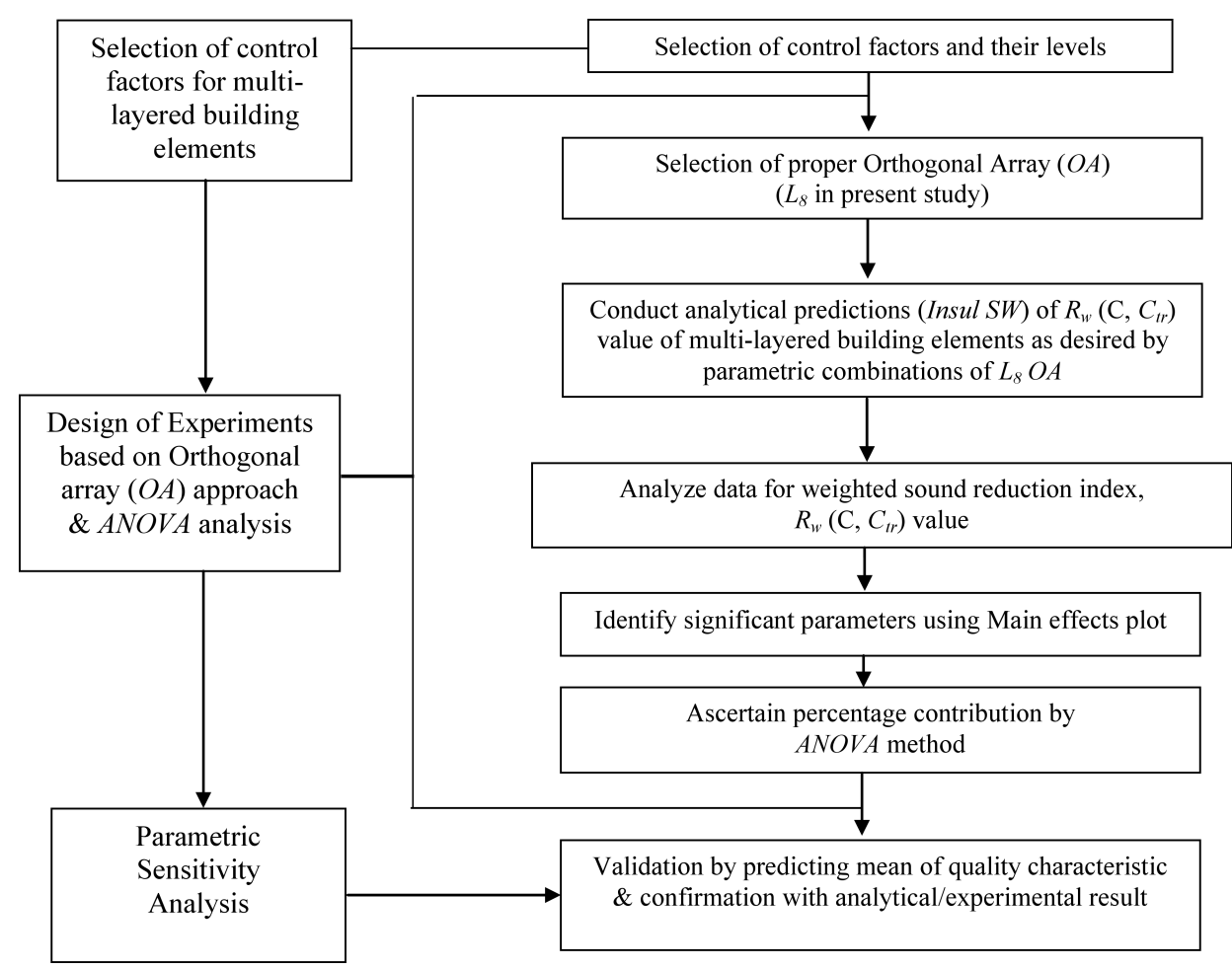

Fig. 2. Methodology adopted for parametric sensitivity analysis of factors affecting sound insulation of multi-layered building elements. 
portance of the parameters on single number ratings is evaluated in terms of percentage contributions using Analysis of Variance ( $A N O V A)$. The final step in Taguchi method is to predict and confirm the quality characteristic using the determined optimal design parameters.

\section{Taguchi analysis}

\subsection{Multi-layered Concrete Constructions}

The increase in sound insulation of masonry constructions attached with gypsum boards is evident from experimental investigations reported (GUILLEN et al., 2008). It is imperative to analyze the significance of various parameters affecting the sound insulation characteristics for development of highly insulative facade constructions. The attachment of gypsum boards via non-load bearing steel studs to masonry constructions and cavity filled with absorptive material is considered to be the preferred configuration. Thus, the selection of control factors and their levels are made on the basis of experience gained in laboratory investigations conducted in Reverberation chambers at Acoustics Division, National Physical Laboratory, New Delhi and from exhaustive literature review on the subject. Seven control factors, namely $A$ to $G$ identified at two levels were investigated using an $L_{8}$ orthogonal array, whereby the intersections are considered to be negligible. The array has 8 rows and 7 columns and each row represents an experimental run, while each column accommodates a specific process parameter. Table 1 represents the selected parameters at two levels. The gypsum boards thickness has been chosen to either one layer of thickness $13 \mathrm{~mm}$, or two layers attached constituting a total thickness of $26 \mathrm{~mm}$, while lightweight concrete thickness is varied from $90 \mathrm{~mm}\left(117 \mathrm{~kg} / \mathrm{m}^{2}\right)$ to $190 \mathrm{~mm}\left(247 \mathrm{~kg} / \mathrm{m}^{2}\right)$. The attachment of gypsum board can be done by various methods viz., wood studs creating cavity depth

Table 1. Selected parameters at different levels.

\begin{tabular}{|c|l|c|c|}
\hline \multicolumn{2}{|c|}{ Parameters } & Level 1 & Level 2 \\
\hline$A$ & Concrete Thickness & $90 \mathrm{~mm}$ & $190 \mathrm{~mm}$ \\
\hline$B$ & Gypsum board Thickness & $16 \mathrm{~mm}$ & $13 \mathrm{~mm}$ \\
\hline$C$ & $\begin{array}{l}\text { No of Gypsum board layers } \\
\text { Attached to concrete }\end{array}$ & One & Two \\
\hline$D$ & Type of Studs & Steel & Wood \\
\hline$E$ & Stud frame & Single & $\begin{array}{c}\text { Studs } \\
\text { with } \\
\text { Resilient } \\
\text { rail }\end{array}$ \\
\hline$F$ & $\begin{array}{l}\text { Density of Sound Absorbing } \\
\text { Material (SAB) in Cavity }\end{array}$ & $12.2 \mathrm{~kg} / \mathrm{m}^{3}$ & $11.7 \mathrm{~kg} / \mathrm{m}^{3}$ \\
\hline$G$ & Stud spacing & $400 \mathrm{~mm}$ & $600 \mathrm{~mm}$ \\
\hline
\end{tabular}

of $40 \mathrm{~mm}$, resilient channels $13 \mathrm{~mm}$, steel studs creating cavity depth of $65 \mathrm{~mm}$, Z-bar channels creating cavity depth of $75 \mathrm{~mm}$ etc. (BRADLEY, BIRTA, 2001a; Bradley, Gover, 2011). The present investigation utilizes two types of studs viz., steel and wood studs attached to concrete wall via single or studs with resilient rails. Resilient rails are usually steel channels fixed to the studs, with the wall or ceiling linings fixed to the resilient rail rather than directly to the stud so as to prevent direct vibration transmission via the stud by acting as a soft spring between linings and stud (Insul. co.nz).

The selection of two levels for stud spacing is chosen on the basis of widely used configurations. Additionally density of sound absorbing material is also considered for ascertaining its significance in affecting the sound insulation characteristics. The two options used for sound absorbing material are $65 \mathrm{~mm}$ glass fibre batt $(G F B)$ of density $11.7 \mathrm{~kg} / \mathrm{m}^{3}$ (flow resistivity $=3600 \mathrm{mks}$ rayls $/ \mathrm{m}$ ) and $89 \mathrm{~mm}$ batt of density $12.2 \mathrm{~kg} / \mathrm{m}^{3}$ (flow resistivity $=4800 \mathrm{mks}$ rayls $/ \mathrm{m}$ ).

The experiments are designed based on orthogonal array technique. An $L_{8}\left(2^{7}\right)$ orthogonal array is used in the present analysis as shown in Table 2 . Thus, $90 \mathrm{~mm}$ concrete attached with $16 \mathrm{~mm}$ gypsum board via single steel studs spaced $400 \mathrm{~mm}$ apart and GFB $89 \mathrm{~mm}$ batt as absorptive material in cavity is first experiment as decided by $L_{8}$ orthogonal array. These parameters are categorized at two levels e.g. $A_{1}, A_{2} ; B_{1}, B_{2}$ to $G_{1}$ and $G_{2}$ etc. The goal of analysis is to investigate about the masonry-aircavity-gypsum configuration having maximum value of sound insulation. As such, the singlenumber rating $R_{w}+C_{t r}$ is selected to be maximized for such constructions to be used as building facades. So, larger-the-better quality characteristic was implemented. The physical parameters of materials used for calculation in Insul software are tabulated in Table 3.

Table 2. Experimental layout using an $L_{8}$ Orthogonal array (Taguchi techniques for quality engineering, 1995).

\begin{tabular}{|c|c|c|c|c|c|c|c|}
\hline Experiment No. & $A$ & $B$ & $C$ & $D$ & $E$ & $F$ & $G$ \\
\hline 1 & 1 & 1 & 1 & 1 & 1 & 1 & 1 \\
\hline 2 & 1 & 1 & 1 & 2 & 2 & 2 & 2 \\
\hline 3 & 1 & 2 & 2 & 1 & 1 & 2 & 2 \\
\hline 4 & 1 & 2 & 2 & 2 & 2 & 1 & 1 \\
\hline 5 & 2 & 1 & 2 & 1 & 2 & 1 & 2 \\
\hline 6 & 2 & 1 & 2 & 2 & 1 & 2 & 1 \\
\hline 7 & 2 & 2 & 1 & 1 & 2 & 2 & 1 \\
\hline 8 & 2 & 2 & 1 & 2 & 1 & 1 & 2 \\
\hline
\end{tabular}

The significant parameters are examined to have the highest variation between the average output value $\left(R_{w}+C_{t r}\right)$ for two levels. It is evident from main effects plot in Fig. 3 that optimum levels are $A_{2}$ (190 mm Concrete), $B_{1}$ (16 mm), $C_{2}$ (two gypsum layers), $D_{1}$ (steel 
Table 3. Material physical parameters used in the calculation in Insul software.

\begin{tabular}{|c|c|c|c|c|c|c|c|}
\hline Material & $\begin{array}{c}\text { Density } \\
{\left[\mathrm{kg} / \mathrm{m}^{3}\right]}\end{array}$ & $\begin{array}{c}\text { Thickness } \\
{[\mathrm{mm}]}\end{array}$ & $\begin{array}{c}\text { Surface } \\
\text { weight } \\
{\left[\mathrm{kg} / \mathrm{m}^{2}\right]}\end{array}$ & $\begin{array}{c}\text { Elastic } \\
\text { Modulus } \\
{\left[10^{9} \mathrm{~N} / \mathrm{m}^{2}, \mathrm{GPa}\right]}\end{array}$ & $\begin{array}{c}\text { Poisson } \\
\text { Ratio } \\
(\mu)\end{array}$ & $\begin{array}{c}\text { Loss } \\
\text { Factor } \\
(\eta)\end{array}$ & $\begin{array}{c}f_{c} \\
{[\mathrm{~Hz}]}\end{array}$ \\
\hline Gypsum board & 690 & 13 & 9 & 2.01 & 0.3 & 0.01 & 2923 \\
\hline Gypsum board & 690 & 16 & 11 & 2.01 & 0.3 & 0.01 & 2375 \\
\hline Concrete & 1300 & 90 & 117 & 3.697 & 0.3 & 0.015 & 427 \\
\hline Concrete & 1300 & 190 & 247 & 3.697 & 0.3 & 0.015 & 202 \\
\hline
\end{tabular}

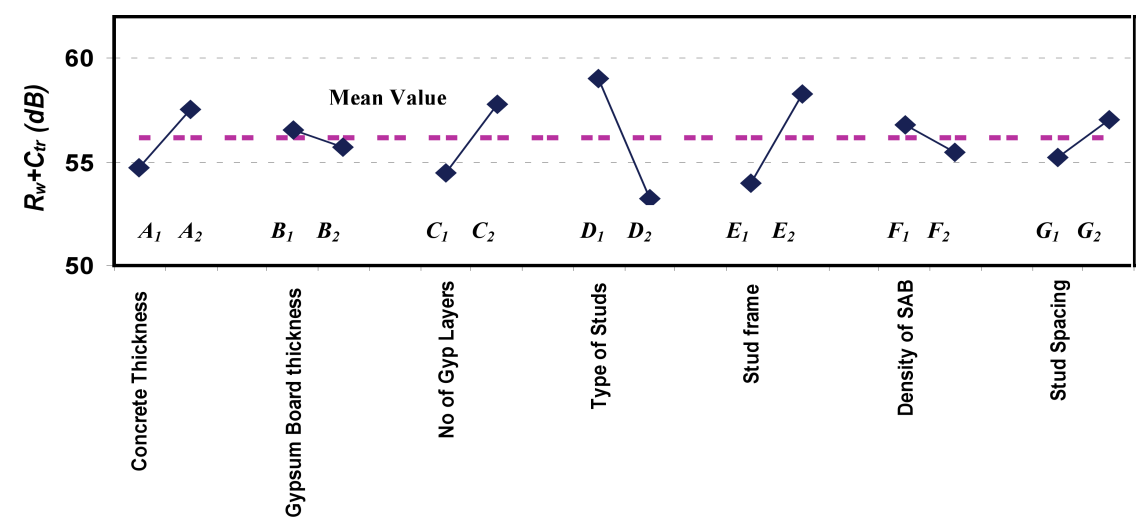

Fig. 3. Main effects plot of various parameters on $R_{w}+C_{t r}(\mathrm{~dB})$ of concrete sandwich constructions with gypsum boards.

stud), $E_{2}$ (stud with resilient rail), $F_{1}\left(12.2 \mathrm{~kg} / \mathrm{m}^{3}\right)$ and $G_{2}(600 \mathrm{~mm}$ stud spacing) respectively. The dotted line represents the mean value of $R_{w}+C_{t r}$ for two levels of parameters $A$ to $G$.

ANOVA usage in Taguchi methods felicitates the computation of variance of all the factors affecting the output. The methodology reveals the significant factors affecting the design output. The measure of relative significance is ascertained by an $F$-test, whereby the factors having high $F$-ratio are confirmed as significant factors. Usually, when $F>4$, it means that the change of the design parameter has a significant effect on the quality characteristic (YANG et al., 1998). The in-active and smaller effects are added together to obtain a non-zero estimate of the error variance called 'pooling up' which can be used to combine factors or interaction effects with low magnitude of sum of squares (Taguchi techniques for quality engineering, 1995). The ANOVA analysis reveals optimum parameters to be $A_{2} C_{2} D_{1} E_{2} G_{2}$ as shown in Table 4 . The type of studs and stud frame is observed to be the prominent factors affecting sound insulation followed by number of gypsum board layers and concrete thickness. Resilient channels used on one or both faces of single rows of stiff studs viz., wood studs or load bearing steel studs help to overcome the peripheral transmission through header and sole plates and thus improves the sound transmission loss considerably, allowing the sound absorptive material in cavity to be effective (WARNOCK, QUIRT, 1997).

Table 4. Results of Analysis of Variance (ANOVA) for $R_{w}+C_{t r}$ of concrete sandwich constructions with gypsum boards.

\begin{tabular}{|c|l|c|c|c|c|c|}
\hline \multicolumn{2}{|c|}{ Parameter } & $D O F$ & Sum of squares & Mean squares & $F$-ratio & Contribution [\%] \\
\hline$A$ & Concrete Thickness & 1 & 15.125 & 15.125 & $7.18^{*}$ & 8.73 \\
\hline$C$ & No of Gypsum Layers & 1 & 21.125 & 21.125 & $9.94^{*}$ & 12.76 \\
\hline$D$ & Type of Studs & 1 & 66.125 & 66.125 & $31.12^{*}$ & 42.99 \\
\hline$E$ & Stud Frame & 1 & 36.125 & 36.125 & $17.0^{*}$ & 22.84 \\
\hline$G$ & Stud Spacing & 1 & 6.125 & 6.125 & $2.88^{* *}$ & 2.69 \\
\hline \multicolumn{2}{l|}{ Pooled Error $(B, F)$} & 2 & 4.25 & 2.125 & & 9.99 \\
\hline \multicolumn{2}{l}{ Total } & 7 & 148.875 & & & 100.00 \\
\hline
\end{tabular}

* Factors are significant at $90 \%$ confidence level.

${ }^{* *}$ Factor is not significant at $90 \%$ confidence level. 
The use of $65 \mathrm{~mm}$ steel studs instead of wood furring strips would provide a bigger air space and wallboard would be decoupled from concrete block (WARNOCK, 1985). The density of sound absorbing material and gypsum board thickness are pooled up as these have been observed to be statistically insignificant; while stud spacing is statistically insignificant at $90 \%$ confidence level as $F$-ratio is less than $F_{0.10 ; 1 ; 3}=5.54$. Figure 4 shows the percentage contribution of each parameter on $R_{w}\left(C, C_{t r}\right)$ value as determined by $A N O V A$ approach without pooling up the insignificant parameters.
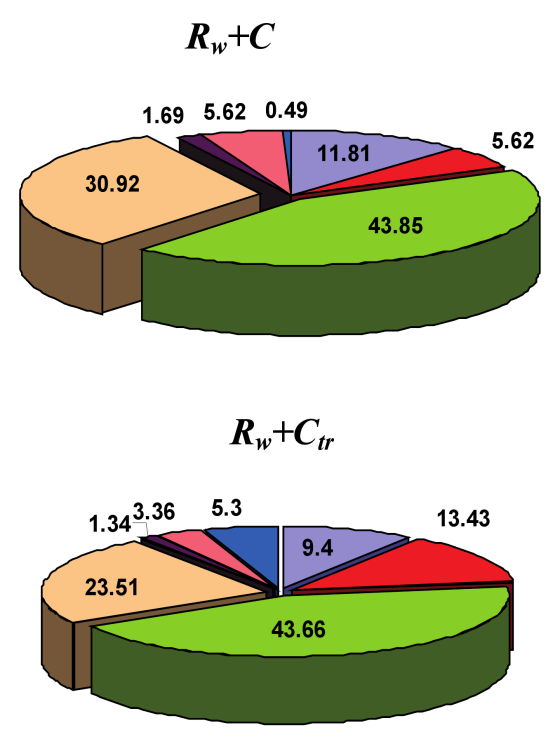

\begin{tabular}{|l|}
\hline Concrete Thickness \\
$\square$ No of Gypsum Layers \\
$\square$ Type of Studs \\
$\square$ Stud Frame \\
$\square$ Density of SAB \\
$\square$ Stud Spacing \\
$\square$ Pooled Error
\end{tabular}

Fig. 4. Percentage contribution of various parameters on $R_{w}\left(C, C_{t r}\right)$ of sandwich concrete constructions.

It can be observed that single-number rating, $R_{w}+$ $C_{t r}$ is significantly affected by addition of gypsum layers as compared to $R_{w}+C$. The percentage contribution of concrete thickness $(11.81 \%)$ is significant as compared to the number of gypsum layers $(5.62 \%)$ on $R_{w}+C$. The type of stud and stud frame are the vital parameters controlling the sound insulation characteristics. The attachment via resilient rails thus is a good solution for enhancing sound transmission loss provided all installation perspectives should be considered (LoVERDE, Dong, 2009).

\subsection{Sandwich Gypsum Constructions}

The application of taguchi method is extended for sandwich gypsum constructions for analyzing the piv- otal factors affecting sound insulation characteristics. Six control factors viz., gypsum board thickness, no of layers, type of studs, type of steel stud frame, density of absorptive material and stud spacing were selected for the investigation. Each of the six factors is considered at two levels as shown in Table 5 and identified as $A^{\prime}$ to $F^{\prime}$, whereby parameter $G^{\prime}$ is zero in this case. The gypsum boards thickness has been chosen to either one layer each side constituting a thickness of $26 \mathrm{~mm}$, or using two layers each side constitutes a thickness of $52 \mathrm{~mm}$. The selection of two levels for stud spacing is chosen on the basis of widely used configurations, while the sound absorbing material used is glass fibre $65 \mathrm{~mm}$ and $89 \mathrm{~mm}$ batt. The main choices considered for steel stud frame are single non-load bearing steel stud and double studs configuration. Double studs are constructed by erecting two separate frames, usually $25 \mathrm{~mm}$ apart and lining the outside of each frame typically with 1 or 2 layers of plasterboard and as such there is no physical contact between each side of the wall, the only transmission path is via the air cavity. Thus, appreciably high sound insulation can be achieved with this configuration (Insul. co.nz). The experiments are designed based on orthogonal array technique. An $L_{8}\left(2^{7}\right)$ orthogonal array is also used in the present analysis.

Table 5. Selected parameters at different levels.

\begin{tabular}{|c|l|c|c|}
\hline \multicolumn{2}{|c|}{ Parameters } & Level 1 & Level 2 \\
\hline$A^{\prime}$ & Gypsum board thickness & $13 \mathrm{~mm}$ & $16 \mathrm{~mm}$ \\
\hline$B^{\prime}$ & $\begin{array}{l}\text { No of Gypsum board layers } \\
\text { attached each side }\end{array}$ & Two & One \\
\hline$C^{\prime}$ & Type of Studs & Wood & Steel \\
\hline$D^{\prime}$ & Stud frame & Double & Single \\
\hline$E^{\prime}$ & $\begin{array}{l}\text { Density of Sound Absorb- } \\
\text { ing Material in Cavity }\end{array}$ & $11.7 \mathrm{~kg} / \mathrm{m}^{3}$ & $12.2 \mathrm{~kg} / \mathrm{m}^{3}$ \\
\hline$F^{\prime}$ & Stud spacing & $600 \mathrm{~mm}$ & $400 \mathrm{~mm}$ \\
\hline
\end{tabular}

As $R_{w}+C$ is the preferred single-number rating suggested by recent studies (RASMUSSEN, 2010; RASMUSSEN, Rindel, 2010; SCHOLL et al., 2011) for sound insulation between dwellings, the present investigations focus on optimizing $R_{w}+C$ value for sandwich gypsum partitions. The objective of present analysis is to investigate about the sandwich drywall configuration having maximum value of $R_{w}+C$. So, largerthe-better quality characteristic was implemented. Figure 5 shows the main effects plot for various parameters. It can be observed that $A_{2}^{\prime}(16 \mathrm{~mm}$ gypsum board), $B_{1}^{\prime}$ (two gypsum layers each side), $C_{2}^{\prime}$ (steel stud), $D_{1}^{\prime}$ (double steel stud), $E_{2}^{\prime}\left(12.2 \mathrm{~kg} / \mathrm{m}^{3}\right)$ and $F_{1}^{\prime}$ (600 mm stud spacing) are the optimum parameters. 


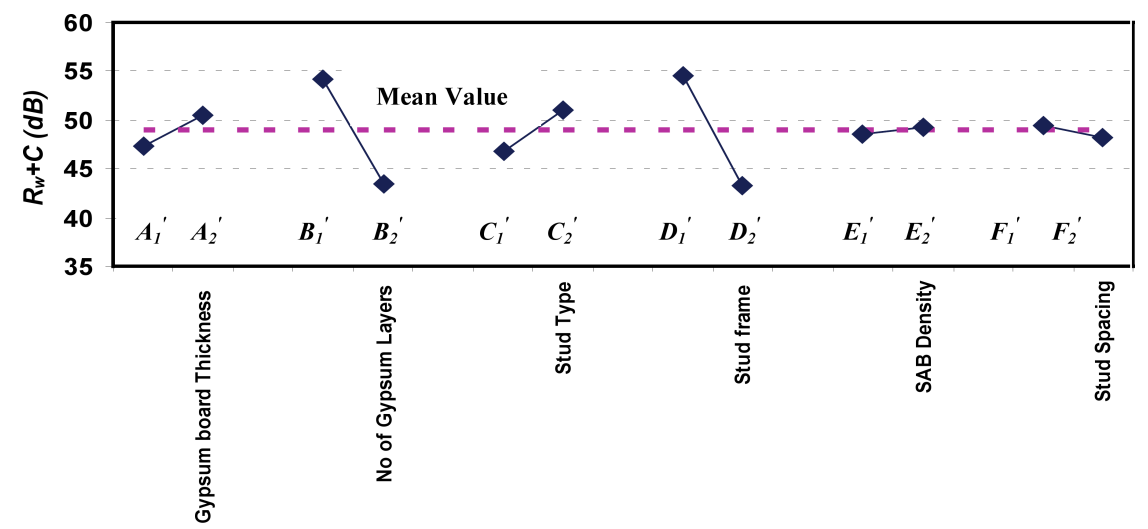

Fig. 5. Main effects plot of various parameters on $R_{w}$ of sandwich gypsum boards constructions.

The ANOVA analysis reveals that optimum levels are $A_{2}^{\prime} B_{1}^{\prime} C_{2}^{\prime} D_{1}^{\prime}$ as shown in Table 6 . The stud frame and number of gypsum layers attached plays a prominent role in controlling the sound insulation characteristics. The type of stud viz., wood or steel is also an important factor. The density of sound absorbing material (or thickness) and stud spacing are statistically insignificant at $90 \%$ confidence level and constitutes the pooled error.

The benefits available from using sound absorbing materials with higher flow resistivity and density are evident at higher frequencies as compared to lower frequencies (WARNOCK, QUIRT, NRCC 39272). ANOVA results indicates density or thickness of sound absorptive material to be statistically insignificant. Previous studies in this regard also seem to be inconclusive about definite relationship between density of sound absorbing material and sound reduction index. URIS et al. (1999) observations shows that for frequencies below $1.25 \mathrm{kHz}$, the sound reduction index can be increased by reducing the rock wool density, while for higher frequencies this parameter does not greatly affect the acoustic insulation. The ANOVA approach was repeated for different single-number ratings to ascertain the significance of these parameters. Figure 6 shows the percentage contribution of various parameters on single number ratings, $R_{w}, S T C, R_{w}+C_{t r}$ and $R_{w}+C$ determined using ANOVA approach at $90 \%$ confidence level.

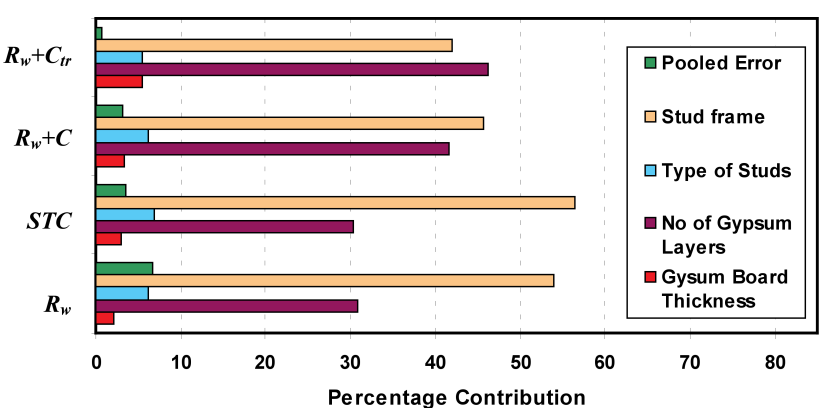

Fig. 6. Percentage contribution of various parameters on single-number ratings as determined from ANOVA method.

It can be observed that the spectrum adaptation terms $\left(C, C_{t r}\right)$ are more sensitive to the number of gypsum layers attached, whereby stud frame is the most important factor in controlling the overall sound transmission loss characteristics. The percentage contribution due to type of stud is less significant $(6 \%)$ in this case as compared to the stud frame.

\subsection{Confirmation Experiment}

The predicted mean for quality characteristic $\left(R_{w}+\right.$ $\left.C_{t r}\right)_{m p}$ is computed as (NALBANT et al., 2007):

$$
\left(R_{w}+C_{t r}\right)_{m p}=\bar{y}+\sum_{i=1}^{n}\left(y_{i}-\bar{y}\right)
$$

Table 6. Results of Analysis of Variance (ANOVA) for $R_{w}+C_{t r}$ of concrete sandwich constructions with gypsum boards.

\begin{tabular}{|l|l|c|c|c|c|c|}
\hline \multicolumn{2}{|c|}{ Parameter } & $D O F$ & Sum of squares & Mean squares & $F$-ratio & Contribution [\%] \\
\hline$A^{\prime}$ & Gypsum board thickness & 1 & 21.125 & 21.125 & $8.59^{*}$ & 3.40 \\
\hline$B^{\prime}$ & No of Gypsum Layers & 1 & 231.125 & 231.125 & $94.02^{*}$ & 41.66 \\
\hline$C^{\prime}$ & Type of Studs & 1 & 36.125 & 36.125 & $14.69^{*}$ & 6.13 \\
\hline$D^{\prime}$ & Stud Frame & 1 & 253.125 & 253.125 & $103.0^{*}$ & 45.67 \\
\hline \multicolumn{2}{|l|}{ Pooled Error $\left(E^{\prime}, F^{\prime} \& G^{\prime}\right)$} & 3 & 7.375 & 2.458 & & 3.14 \\
\hline \multicolumn{2}{|l}{ Total } & 7 & 548.875 & & & 100.00 \\
\hline
\end{tabular}

${ }^{*}$ Factors are significant at $90 \%$ confidence level. 
where $\bar{y}$ is the average of performance characteristic, $R_{w}\left(C, C_{t r}\right)$ corresponding to all eight experiments in Table 2 and $n$ is no of parameters considered that significantly affect the performance characteristic, $y_{i}$ is mean value of individual parameters $\left(A_{2} C_{2} D_{1} E_{2} G_{2}\right)$ and $\left(A_{2}^{\prime} B_{1}^{\prime} C_{2}^{\prime} D_{1}^{\prime}\right)$ at optimum levels. The predicted $\left(R_{w}+C_{t r}\right)_{m p}$ value for concrete block along with gypsum boards is calculated using Eq. (4) as $65.0 \mathrm{~dB}$. Similarly, the predicted $\left(R_{w}+C\right)_{m p}$ value for sandwich gypsum construction is calculated using Eq. (4) as $63.6 \mathrm{~dB}$. The confirmation experiment was performed by analytically predicting the single-number rating for optimal configuration. The optimum configuration as predicted from software has $R_{w}+C_{t r}$ value of $65 \mathrm{~dB}$ in case of concrete sandwich constructions and $R_{w}+C$ value of $64 \mathrm{~dB}$ in case of sandwich gypsum construction, which closely matches with that predicted from Taguchi method. The close agreement of optimum value predicted from taguchi method with the experimentally (or analytically) observed value also confirms that no important factor is missing in the present analysis (Total Quality Management, 1999). It may be noted here that the confidence interval associated with mean value determined from Eq. (4) can also be calculated by simple mathematical formulation (Taguchi techniques for quality engineering, 1995).

\section{Discussion}

The parametric sensitivity of various factors controlling the sound insulation is instrumental in designing sandwich constructions for optimizing sound insulation characteristics. The addition of gypsum layers is helpful in accentuating the overall sound transmission loss due to increase in the mass. Theoretical simulation reveals an increment of $R_{w}$ value by $12 \mathrm{~dB}$ on changing double layers gypsum board each side to four layers each side when connected via double steel studs. The type of stud has been investigated in present study to be critical parameter controlling the sound insulation characteristics in consistent with WARNOCK, QUIRT (1997) experimental observations. Double studs stand to be the preferred frame owing to greater mechanical decoupling between two sides of partition achieved through two separate rows of studs. The staggered studs and resilient channels also show good performance. The primary structural resonance at low frequency is shifted to a lower frequency with addition of resilient channels along with steel studs. Analysis of the experimental observations for some specific gypsum and masonry constructions tested and reported by Bradley, Gover (2011) (reported in $S T C$ and average sound transmission loss) in terms of $R_{w}(C$, $\left.C_{t r}\right)$ reveals some of the major points helpful in understanding the effect of parameters discussed in Table 1 and 5 as:
- Changing from steel studs to double steel studs increases $R_{w}+C$ value by 10 to $12 \mathrm{~dB}$ for studs spaced $610 \mathrm{~mm}$ apart.

- Attachment of gypsum board $(16 \mathrm{~mm})$ via steel studs to $190 \mathrm{~mm}$ concrete significantly arrests the coincidence dip encountered at $2.5 \mathrm{kHz}$ in case of attachment of gypsum wall board to masonry concrete with wood studs and thus $R_{w}$ increases by $6 \mathrm{~dB}$, while $R_{w}+C_{t r}$ increases by $7 \mathrm{~dB}$. The sound transmission loss plot shows dip at $125 \mathrm{~Hz}$ in case of attachment of gypsum board via resilient channels alone that affects the low frequency sound insulation.

- $R_{w}+C$ value increments by $3-4 \mathrm{~dB}$ by changing $13 \mathrm{~mm}$ gypsum board to $16 \mathrm{~mm}$ gypsum board for $406 \mathrm{~mm}$ stud spacing, while there is no appreciable improvement for $610 \mathrm{~mm}$ stud spacing

- The increase in stud spacing from $406 \mathrm{~mm}$ to $610 \mathrm{~mm}$ increases $R_{w}+C$ value by $1 \mathrm{~dB}$ for $16 \mathrm{~mm}$ gypsum layer each side attached via steel studs (SS65). In case of single $13 \mathrm{~mm}$ gypsum layers each side, the structural resonance at $125 \mathrm{~Hz}$ is modified (by $8 \mathrm{~dB}$ ) and thus $R_{w}+C$ value increments by $5 \mathrm{~dB}$.

- The increase in stud size (or stud depth) from $65 \mathrm{~mm}$ to $90 \mathrm{~mm}$ modifies low frequency resonance and shifts to lower frequency and as such $R_{w}+C$ value for $16 \mathrm{~mm}$ gypsum layer each side increments by $2 \mathrm{~dB}$ for $406 \mathrm{~mm}$ stud spacing and by $4 \mathrm{~dB}$ for $610 \mathrm{~mm}$ stud spacing.

- On changing from single layer to two layers of gypsum board each side attached via single or double steel studs $610 \mathrm{~mm}$ spaced part, the increment in $R_{w}+C$ value by $8-10 \mathrm{~dB}$ is observed.

These observations are consistent with the Taguchi analysis, wherein the stud frame, type of studs and number of gypsum layers are investigated to be the prominent factors. ANOVA approach reveals stud spacing insignificant at $90 \%$ confidence level in case of structural breaks present in the multi-layered walls consistent with QUIRT (1985) observations. The sound insulation provided by the drywall constructions can be thus significantly enhanced by combination with masonry constructions for its suitability for building facades. The overall affect shall not only be the accentuated sound transmission loss, but also more strength, rigidity and durability. Attachment of a single gypsum board $(16 \mathrm{~mm})$ via steel stud to $190 \mathrm{~mm}$ concrete block and sound absorptive material (65 $\mathrm{mm}$ thick glass fibre batt) in cavity increases $R_{w}$ value by $9 \mathrm{~dB}$ and $R_{w}+C_{t r}$ value by $5 \mathrm{~dB}$, when compared to $190 \mathrm{~mm}$ bare concrete block (WARNOCK, IR586, 1990). The $R_{w}+C_{t r}$ value is further enhanced by $14 \mathrm{~dB}$ by attaching $16 \mathrm{~mm}$ gypsum layers each side to $190 \mathrm{~mm}$ concrete through steel studs and sound absorptive material in cavity. As the primary structural resonances are shifted to lower frequencies with addition of double steel studs, the low 
frequency sound insulation is improved leading to improvement in the spectrum adaptation term for traffic noise, $C_{t r}$. The cavity depth has also to be taken care off for bringing the mass-air-mass resonance (m.a.m) less than $50 \mathrm{~Hz}$ for improving low frequency sound insulation. Thus, for $13 \mathrm{~mm}$ gypsum board attached to concrete wall and cavity filled with absorptive material, the optimum cavity depth for m.a.m $<50 \mathrm{~Hz}$ is calculated from equation $f_{m . a . m}=\frac{43}{\sqrt{M d}}$ (WARNOCK, IR586, 1990) as $82 \mathrm{~mm}$ where $M$ is mass per unit area in $\mathrm{kg} / \mathrm{m}^{2}$ of dry wall and $d$ is distance from drywall to block surface in $\mathrm{m}$. The optimum cavity depth in case of unfilled cavity is calculated as $160 \mathrm{~mm}$ from equation $f_{\text {m.a.m }}=\frac{60}{\sqrt{M d}}$.

The maximum increase in sound transmission loss due to addition of resilient channels is about $15 \mathrm{~dB}$ and only occurs for cavity depths greater than $75 \mathrm{~mm}$ wherein cavity is filled with sound absorbing material (Bradley, Birta, 2001a; 2001b). The $R_{w}+C_{t r}$ value increases by $12 \mathrm{~dB}$ on changing from single steel stud to double steel studs as shown (Fig. 7) in the analytical results predicted from Insul software. Staggered stud is also predicted to show an improved performance with $R_{w}+C_{t r}$ value incremented by $6 \mathrm{~dB}$ on changing from single steel stud to staggered steel stud. The attachment of gypsum layers via either of resilient channels, staggered studs, or double steel studs to concrete wall with sound absorptive material is thus suitable for accomplishing the desired objectives. The implementation of Mixed building technology (BRAGANÇA, PAtrício, 2004) has to be thus brought in wide usage for protecting dwellings from ever increasing traffic noise.

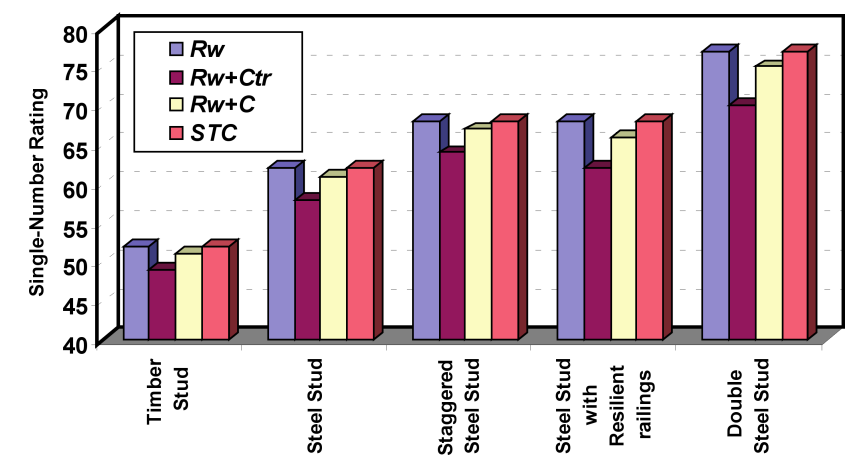

Fig. 7. Single-Number rating for concrete constructions with different types of steel stud frame for attachment of two layers of Gypsum board $(16 \mathrm{~mm})$ to $90 \mathrm{~mm}$ concrete construction.

\section{Conclusions}

The paper presents an application of well known Taguchi method in investigating the significant factors controlling the sound transmission through multilayered constructions involving gypsum boards for their application as building facades and partition walls. Although the study considers the single-number ratings as the performance parameter which may sometimes not present the actual picture as the sound insulation in complete audio frequency range is equally important, yet the use of single-number quantities widely in sound regulation requirements and by manufacturers as well as acousticians necessitates such considerations. An $L_{8}$ standard orthogonal array was used to accommodate seven control factors each at two levels for adjudging their parametric sensitivity. The conclusions drawn from the present work are as follows:

- The key factors controlling the sound insulation characteristics of concrete constructions along with gypsum board attached is the type of studs (43\%), type of stud frame $(22.8 \%)$, followed by number of gypsum layers attached $(12.8 \%)$ and concrete thickness $(8.7 \%)$. The steel stud frame plays a pivotal role in shifting the low frequency m.a.m and flexural resonances. Addition of more gypsum layers can be instrumental in enhancing the sound insulation properties as well and bringing down the mass-airmass resonance. This is evident from the experimental investigations as attaching $16 \mathrm{~mm}$ gypsum board to $190 \mathrm{~mm}$ concrete wall with $65 \mathrm{~mm}$ steel studs and glass fibre batt of $65 \mathrm{~mm}$ included increases $R_{w}$ by $9 \mathrm{~dB}$ and $R_{w}+C_{t r}$ by $5 \mathrm{~dB}$.

- The type of stud frame (45.7\%), number of gypsum layers attached $(41.7 \%)$ plays a significant role in affecting the $R_{w}+C$ value of sandwich gypsum constructions. The type of studs viz., steel or wood has relatively less significance $(6.1 \%)$ as compared to these factors. The spectrum adaptation terms are however more sensitive to the number of gypsum layers attached.

- Double studs are the best preferred attachment followed by staggered studs, steel studs with resilient railings. The stud spacing has also been analyzed to be non critical in controlling the overall sound insulation characteristics especially when structural breaks are provided in the walls consistent with QUIRT (1985) observations. Increasing the depth of cavity (deeper studs or greater separation between row of studs) is helpful in increasing the overall sound transmission loss characteristics provided standing wave resonances aren't induced. An optimum depth of $160 \mathrm{~mm}$ in case of cavity unfilled and $82 \mathrm{~mm}$ in case of cavity filled with sound absorptive material is atleast required for m.a.m $<50 \mathrm{~Hz}$.

- The density and thickness of the sound absorbing material has no major role in deciding sound insulation characteristics although it is evident that inclusion of sound absorbing material will shift the low frequency m.a.m and also interrupt the standing wave resonances creeping in the cavity. The mean value of $R_{w}+C_{t r}$ and $R_{w}+C$ corresponding to optimum conditions is obtained as $65 \mathrm{~dB}$ and $63.6 \mathrm{~dB}$. 
The value calculated from Insul software is $65 \mathrm{~dB}$ for sandwich concrete construction and $64 \mathrm{~dB}$ for sandwich gypsum construction. As the confirmation results are in close agreement with the experimental (or analytical) value, the fact rules out the omission of any other significant factor or interactions between the parameters shown in Table 1 and 5 .

The work presents two case studies pertaining to the optimization of sound insulation by application of Taguchi method for multi-layered building elements utilizing the analytical results predicted on Insul software. Future work in this regard pertaining to the validation of these theoretical results by laboratory experiments can be very beneficial to the building industry for development of highly sound insulative configurations for their applications as building facades and partition walls. The present investigations stresses on the use of dry wall technology in conjunction with masonry constructions for applications in building facades in areas wherein high sound insulation is must for combating the outside traffic noise. Although the costs associated and practical complications involved are much higher, yet the use of both these can be instrumental in achieving the long term noise abatement objectives.

\section{Acknowledgments}

Authors specially acknowledge the reports \& papers published by experts of $N R C$ Canada, IR-586, $I R C-I R-761, I R C$-IR-818, IRC-RR-314, NRCC-36135 etc. whose results have been very much helpful for preparation of the paper. Authors thank Mr. Omkar Sharma for his valuable guidance and Mr. K. Ballagh of MDA, Auckland for procurement of Insul software. Authors also thank the anonymous reviewers for their valuable comments and suggestions.

\section{References}

1. Amundsen A.H., Klæboe R., Aasvang G.M. (2011), The Norwegian facade insulation study: the efficacy of facade sound insulation in reducing noise annoyance due to road traffic, J. of Acoustical Society of America, 129, 3, 1381-1389.

2. António J.M.P., TAdeu A., Godinho L. (2003), Analytical evaluation of the acoustic insulation provided by double infinite walls, J. of Sound and Vibration, 263, 113-129.

3. Ballagh K.O. (2004), Accuracy of prediction methods for sound transmission loss, Inter-noise, http://www.insul.co.nz/download/Paper586-BallaghNew.PDF.

4. Besterfield D.H., Besterfield C.M., BesterField G.H., Besterfield S.M. (1999), Total Quality management, Prentice Hall, Chapter 4.

5. Bradley J.S., Birta J.A. (2000), Laboratory measurements of the sound insulation of building facade elements, IRC Internal Report, IRC IR-818.
6. Bradley J.S., Birta J.A. (2001a), A simple model of the sound insulation of gypsum board on resilient supports, Noise Control Engg. J., 49, 216-223.

7. Bradley J.S., Birta J.A. (2001b), On the sound insulation of wood stud exterior walls, J. of Acoustical Society of America, 110, 3086-3096.

8. Bradley J.S., Gover B.N. (2011), Selecting walls for speech privacy, IRC report RR-314.

9. BragançA L., Patrício J. (2004), Case study: Comparison between the acoustic performance of a mixed building technology building and a conventional building, Building Acoustics, 11, 1, 79-90.

10. Garg N., Kumar A., Maji S. (2013), Practical concerns associated with single number ratings in measuring sound transmission loss properties of partition panels, Archives of Acoustics, 38, 1, 115-124.

11. Guillen I., URis A., Estella H., Llinares J., Llopsis A. (2008), On the sound insulation of masonry wall facades, Building and Environment, 43, 523-529.

12. Halliwell R.E., Nightingale T.R.T., WarNOCK A.C.C., BiRTA J.A. (1998), Gypsum board walls: Transmission loss data, NRC Report No. IRC-IR-761.

13. Insul Software Manual, http://www.insul.co.nz/download/Insulv6Manual.pdf.

14. Kurra S. (2012), Comparison of the models predicting sound insulation values of multi-layered building elements, Applied Acoustics, 73, 575-589.

15. LoVerde J., Dong W. (2009), Quantitative comparison of resilient channel design and installation methods, Internoise, http://www.pac-intl.com/pdf/ IN09_737_Submitted.pdf.

16. Nalbant M., Gökkaya H., Sur G. (2007), Application of Taguchi method in the optimization of cutting parameters for surface roughness in turning, Materials and Design, 28, 1379-1385.

17. Patterson M.J. (2004), Recent changes to the sound insulation provisions of the Building code of Australia, Proc. of Acoustics, 3rd to 5th November, Gold Coast, Australia.

18. QuirT J.D. (1985), Sound transmission through building components, Canadian Building Science Insight.

19. Rasmussen B., Rindel J.H. (2010), Sound insulation between dwellings - Descriptors applied in building regulations in Europe, Applied Acoustics, 71, 3, 171-180.

20. Rasmussen B. (2010), Sound insulation between dwellings - Requirements in building regulations in Europe, Applied Acoustics, 71, 4, 373-385.

21. Ross P.J. (1995), Taguchi techniques for quality engineering, Mc Graw Hill, New York.

22. Scholl W., Lang J., Wittstock V. (2011), Rating of Sound Insulation at Present and in Future. The Revision of ISO 717, Acta Acustica united with Acustica, 97, 686-698.

23. Uris A., Llopis A., Llinares J. (1999), Effect of the rockwool bulk density on the airborne sound insulation 
of lightweight double walls, Applied Acoustics, 58, 327331.

24. WARNOCK A.C.C. (1985), Factors affecting sound transmission loss, Canadian Building Science Insight, CBD 239.

25. WARNOCK A.C.C. (1990), Sound transmission loss measurement through $190 \mathrm{~mm}$ and $140 \mathrm{~mm}$ blocks with added dry wall and through cavity block walls, NRC Canada, Internal Report No. 586.

26. WARNOCK A.C.C. (1993), Sound transmission through slotted concrete blocks with attached gypsum board, J. of Acoustical Society of America, 94, 2713-2720.
27. WARnock A.C.C. (1998), Controlling sound transmission through concrete block walls, Construction Technology Update No. 13.

28. Warnock A.C.C., Quirt J.D. (1997), Control of sound transmission through gypsum board walls, Construction Technology Update No. 1.

29. WARNock A.C.C., QUIRT J.D., Sound transmission through Gypsum board walls, NRCC-39272.

30. YANG W.H., TARNG Y.S. (1998), Design optimization of cutting parameters for turning operation based on the Taguchi method, J. of Materials Processing Technology, 84, 122-129. 